graphs and graphical representations are good and there are excellent reference sections at the end of each chapter. In spite of its shortcomings, this is a useful book for all those interested in the chemistry of natural products, pest control and in the new discipline of chemical ecology. J. D. THOMAs

\section{West Indian Butterflies}

Butterflies of Trinidad and Tobago. By Malcolm Barcant. Pp. $314+28$ plates. (Collins: London, February 1971.) $£ 2.75$.

BUTTERFLY books can be divided broadly into two classes according to their degree of specialization. There are, on the one hand, those intended for the specialist, the genuine entomologist, and, on the other, books written primarily for the collector who wishes to be able to identify what he has caught fairly rapidly, to know where to look for the ones he has not yet caught, the best time of year to see them on the wing and something of their life histories. This latter class may be termed the more "popular" books and Malcolm Barcant's book falls into this class, although this is not to say that its scientific standard is not high.

While there are popular books on the butterflies of Africa, Europe, Australia and North America, no one so far has tackled the enormous task of setting out a pictorial, reasonably cheap edition which deals with South America. Yet the rain forests of the Amazon contain many of the most exotic, certainly the largest number of species of any region in the world. Quite a number of species on the South American mainland, however, "spill over" into Trinidad and this fact will undoubtedly make a book on the butterflies of Trinidad of interest to collectors of the world's butterflies.

It should be remembered, however, that this book is written primarily for the collector who is actually in Trinidad, for its general layout will strike the foreigner as rather odd because they are grouped first by habits and habitats, for example, "the water drinkers", "the shade dwellers", and then by rarity. Thus a specialist in Heliconius must search in different parts of the book for closely allied species. Although there is a check list of all species, there is no alphabetical index and this is at times inconvenient. The classification by rarity applies only to Trinidad, for some of the species listed as of "exceptional rarity" are common on the mainland as evidenced by the fact that they can be bought in England for a fraction of a pound. The 16 colour plates are excellent, and one wishes that the other 12 plates which are photographs on glossy paper had also been in colour. At the same time one cannot help feeling that some of the illustrations have been "wasted", for example, there are two species of Prepona illustrated topside only. Identification of these species lies primarily in the undersides, which are described as "two shades of brown" and "totally fawn". These descriptions could fit any of half a dozen other species of Prepona. Two other species of Prepona not illustrated underside are described as "silver with irregular black lines" and "silver with indistinct black markings". The individual illustrations on the plates are not numbered but separate outline sketches on the facing pages are numbered and this can cause the reader extra labour and possibly slight annoyance.

In spite of these few shortcomings the book will undoubtedly be popular among collectors and lovers of these gorgeous insects whether or not they live in Trinidad.

\section{E. R. Laithwaite}

\section{Traces in Time}

Principles of Paleontology. By David M. Raup and Steven M. Stanley. (A Series of Books in Geology.) Pp. $x+$ 388. (Freeman: San Francisco and Reading, March 1971.) $£ 4.80$.

THE authors and publishers are to be congratulated on producing this lucid introductory palaeontology textbook which should have universal appeal. Its emphasis, which is clearly outlined in the preface and on the dust jacket, is directed at explaining the principles on which palaeontological concepts are formulated. It guides the reader progressively from mastering the techniques of analysing simple case histories to grappling with the more abstruse evolutionary tenets.

Just under half the volume is concerned with the description and classification of fossils. This is introduced by an extensive quantitative evaluation of the chances of preservation throughout time, followed by an extremely clear discussion of ontogeny and its significance. From thence the unitary value of the fossil population is discussed in terms of Recent analogies which lead naturally to an introduction of the species concepts. Having thus stimulated the reader, the remaining 32 pages of this section give instruction on how to categorize and identify materials to professional standard.

The second half of the book is devoted to the uses of palaeontology. This is introduced by a theoretical discussion of adaptation and functional morphology which is carefully based on a blending of biological observations with mathematical principles. In this chapter a major palaeontological advance is made by showing how the coiled "shell" form may be related to the analysis of the logarithmic spiral as exemplified by an analogue computer model. From thence we progress to the influence of mechanics in terms of dinosaur jaw movements, problems of trilobite vision, and the life habits of cephalopods, brachiopods and bivalves. The succeeding chapter on palaeoecology, which is extremely competent, discusses the Recent ecosystem as its reference point and shows how the resulting principles can be applied to the fossil record. Equal weighting is given to the succeeding section on evolution which, though more theoretical in its treatment, is copiously illustrated with appropriate line diagrams. But, by comparison, its practical counterpart on biostratigraphy, which follows the evolutionary chapter, is surprisingly succinct. As explained in the preface, the final chapter on palaeontological data in geophysics and geochemistry is tantalisingly brief: but this is perhaps inevitable in that at the time of going, to press this was still a novel research field fraught with problems inappropriate to the beginner.

Each chapter is introduced by a key statement of intent, subdivided by appropriate headings, and closed with a paragraph on the state of knowledge and assessment of the potential of the theme. This is followed by a suggested reading list of four to six texts which are particularly relevant to that chapter. Thus the book is laid out to conform to American academic educational standards at their best. Its literary style is similarly particularly suited to such an audience, which may render it a little difficult to the non-English-speaking reader. But the contents of the book leave no doubt that it is without rival in international circles; it is conceptually challenging, visually pleasing and easy to read, with a reliable cross index system. The bibliography contains reference to 241 texts of which more than 90 per cent are in English language publications (13 texts in German and two in French), with a heavy bias to recent information (36 per cent published during 1965-1970, 24 per cent between 1960-1965, 26 per cent in the 1950 s, and 14 per cent pre-1950).

It is difficult to find fault with this book, which has fulfilled the objects of its preface: allometry (pp. 60-61) is passed over rather hastily, "shell" structure is largely omitted, reference to "the Cretaceous 'Chalk' of England" (p. 279) should probably read-chalknot-"Chalk", and the definition of stromatolites as "typically layered cabbage-like structures" (p. 215) could cause confusion for those expecting to find a stalk. But these are minor problems. This textbook should be within the means of the serious student who will be frustrated at finding the library copies in continuous use.

Julia A. E. B. Hubbard 